action of the respiratory forces more speedy and certain. The rarity of emphysema in cases of hysterical cough, even when severe and long-continued, seems to lend confirmation to this view.

Lugar-place, Glasgow.

\section{THE EARLY PHASES OF DISEASE.}

BY HARRY CAMPBELL, M.D.,

PHYSICIAN TO THE NORTH-WEST LONDON HOSPITAL.

THE advance of clinical medicine during the past halfcentury is matter for congratulation; be it observed, however, that this advance has been chiefly in respect of the more obtrusive kinds of disease, and of these, again, in their welldeveloped phases. Thus, pulmonary phthisis, pleurisy, valvular affections of the heart, nephritis, cerebral bæmorrhage, typhoid fever, and the like, which have an unmistakable morbid anatomy and a definite and easily recognisable symptomology, have been laboriously studied so far as what may be called their "obtrusive phases" are concerned. Such obtrusive disorders are at this moment being minutely observed all over the civilised world, and the discovery of one hitherto undescribed, such as acromegaly, is everywhere hailed with eager interest. But, while much attention has been paid to these diseases of the hospital ward, those which are less ostentatious in their manifestations, revealing themselves almost wholly by subtle functional disturbance, have received comparatively little notice ; and diseases of the former class also, while yet in their initial stages, have shared the same meglect, as well as a host of minor ailments which do not, as a rule, pass on to severer forms. The cause of this neglect I conceive to be twofold. In the first place, the diseases which manifest themselves obtrusively lend themselves readily to study, their symptoms being in a large degree objective, and thus appealing directly to the senses of the observer; whereas in the less obtrusive class of disorders the objective symptoms are fewer and subtler, while the subjective symptoms, upon which he has consequently chiefly to depend, require to be studied with exceptional skill and care. And in the second place, while the former class of diseases are admitted in large numbers into hospital (where, by the way, almost all original work in medicine is done), and can thus be studied at the bedside from day to day, and, if need be, from hour to hour, diseases of the latter class seldom find their way into the ward, and must be studied in the out-patient department, where facilities for careful observation are far fewer, and where, moreover, the large number of cases to be seen in a short time prevents a detailed study of each. The out-patient physician is further hampered in original research by having to give his chief attention to teaching, the duties of which are quite incompatible with that patient and laborious investigation which these less obtrusive forms of disease so especially demand. Now I would advance two propositions which, if sound, should lead to more attention being directed in future to these hitherto neglected fields : (1) All non-traumatic disease is gradual in onset; and (2) it is in its first phase purely functional.

1. That chronic disease begins insidiously is self-evident, but it is not so widely recognised that even acute disease is very generally gradual in its approach - that health rarely, if ever, passes abruptly into disease, unless as a result of accident. The very gradual onset of many diseases has been forcibly impressed upon my mind for a long time past, but it was not until I read Dr. H. Gawen Sutton's thoughtful lectures on pathology that $I$ realised that in this respect acute disease largely falls under the same law as chronic disease. Few maladies are apparently more sudden in their onset than $x$ heumatic fever, but as a matter of fact this affection never attacks a person in sound health; there is always a prodromal stage of enfeebled health. "Before the joints become affected and before there is any sign of local inflammation rheumatic fever is commonly ushered in by anæemia, by dyspeptic symptoms, by increasing weakness, by sweating at pight, with the characteristic sour smell of the perspiration, and by a slight rise of temperature towards evening." (Sutton.) This antecedent phase of ill-health is probably not mere debility, but is a specific functional aberration - one, that is to say, definitely related to rheumatism, constituting, in fact, the initial phase of it, and one which is therefore conceivably capable of recognition. As with acute rheumatism so with acute nephritis-it never attacks a person who is in perfect health. Where there are opportunities of observing a patient just before the acute outbreak something wrong is always detected, though it may not be possible to state precisely what, and thus to warn the medical man of the particular danger that threatens. The same law holds good as regards acute pneumonia, and acute insanity is another disorder which is probably always heralded by definite (mental) symptomatology. Cerebral hæmorrhage, again, so sudden and often so unexpected, is in its usual form but the culmination of a long series of morbid changes which manifest themselves to the careful observer in a very definite way. Not infrequently, indeed, it is possible from observation of tortuous, tense temporals, mental disposition, and knowledge of family history to diagnose in quite young people who are casually met with, and who perhaps are doing their best by injudicious living to increase blood pressure and to hurry on the fatal catastrophe, the commencement of that long chain of morbid events which ends in apoplexy. Dr. Sutton even brings certain of the exanthemata under the same law of gradual onset. It has long been known that the resistance which the human organisation offers to parasites differs from time to time, rising and falling with bodily vigour ; and it is certain that an antecedent enfeebled. state of health shares in the causation of the exanthemata. Dr. Sutton insists upon this especially in regard to typhoid fever; he would seem to imply that the typhoid germ actually cannot flourish in a perfectly healthy individual and that the prevalence of the disease among armies on campaign is due as much to fatigue and privation as to the operation of the specific germ. One must not, however, push the principle of gradual onset too far in the case of the parasitic diseases, for there can be no doubt that certain pathogenic organisms may gain a hold even in the most healthy, resistance being due not so much to a high standard of health as to immunity gained by natural selection and perhaps by other means. It should be noted that the lowered state of vitality which may precede parasitic inoculation is not specific-nota prodromal stage like that which ushers in the disorders previously alluded to. There is therefore hope that from these antecedent phases one may learn to diagnose acute disease before its sudden outburst, just as the inhabitants of a volcanic district have learnt to foretell an eruption by certain well-known signs. And, if there is hope even with respect to these, how much greater hope is there that it will one day be possible to recognise the beginnings of chronic disease, to read the handwriting on the wall while there is yet time to render effective help? Yet it is precisely concerning the earliest phases of chronic disease that ignorance most prevails. Knowledge of a chronic disorder chiefly pertains to that period when it has obtrusively declared itself and our clinical conception of it is too apt to leave its earliest manifestations entirely unconsidered; one does not sufficiently try to detect the commencement of that gradual descent which, only after years it may be, causes the sufferer to seek medical advice. Of such a nature is locomotor ataxy, a disorder that is never diagnosed at its very beginning--nay, that is often not recognised until it has advanced to a stage when it is almost beyond the control of medicine. Yet for years before the definite diagnosis is made the patient may have been suffering from a series of symptoms which, rightly interpreted, would have revealed the real nature of the disease to his physician long before the development of those classical symptoms by which it is known, and also before it had passed beyond the pale of therapeutics. Of all phases of this or of any other chronic disease, that first phase of all, when the individual is hovering on the borderland between health and disease, is the most interesting, the most fascinating to the thoughtful physician, and at the same time the most hopeful. If there have existed opportunities of observing a case of locomotor ataxy for some years before it was recognised as such, it can again and again be traced to those initial phases when, all unconscious of the tragedy that had begun, the victim was going about his life's work, laboriously advancing, it may be, towards the goal of his ambition; we shall picture him as for years remaining stationary and struggling successfully against the unrecognised foe ; and then, after definite manifestations of the disease, it will be remembered how he became less and less able to pursue his work, until finally he was compelled to drop out of the ranks altogether and await the end, henceforth a silent and helpless spectator. All this will be mentally rehearsed, but it is, I say, on the opening scenes of the tragedy that the mind will dwell longest. In the light of subsequent events many incidents of this period will become pregnant with interest, and it will appear strange 
how so fell a process should have escaped discovery for so long. My own impression is that the beginning of most chronic diseases lies much further back than is generally thought-that many a chronic disorder that does not attain its full development till the age of fifty, or after, had begun its silent work in early adult life. I am inclined to think that such is often the case with non-syphilitic locomotor ataxy or granular kidney - nay, even with such a disorder as paralysis agitans.

2. Non-traumatic disease is in its first phases purely functional. "All disease at the outset is purely a functional disturbance, and if we can recognise it early enough we can often ward it off." (Sutton.) It is very necessary to attach a definite meaning to the term "functional" here. By functional disease I understand one in which there is functional aberration without any discoverable structural change to account for it. The qualifying word should be noted, for many diseases that are regarded as functional are dependent upon structural peculiarity that is undiscoverable. Dyspepsia occurring in a perfectly healthy individual as a result of severe mental shock is a functional disorder, pure and simple, but the functional aberrations occurring at the beginning of a case of locomotor ataxy which is purely hereditary - i.e., which is independent of mal-environment-is manifestly due to some structural defect, though such defect is undiscoverable, consisting, it may be, in some peculiarity in the arrangement of atoms in molecules, and of the relation of molecule to molecule and of cell to cell. ${ }^{1}$ Such undiscoverable lesions are, however, so subtle that one may regard all disease as func. tional until the tissues have advanced to a stage of dissolution which is discoverable, up to whish time the possibility of reversion to the normal is (often, at least) very great.

The fact that all non-traumatic diseases tend to begin insidiously and to be purely functional in their initial phases should ever be borne in mind. I know of nothing in medicine that is more important; it shows where progress lies and inspires us with hope for the futare. And this is needed. The inability to cope with disease, such as it is met with in the wards, is sufficiently depressing : too often one has to satisfy oneself with the barren triumph of correct diagnosis. It is of importance to be able to descry the approach of disease from afar, so that physicians, like careful generals, may lay their plan of defence betimes and not be taken unawares. They must, in short, pay more attention than they have done hitherto to the minor manifestations of disease.

Devonshire-street, $\mathbf{W}$.

\section{ON CEREBRINE ALPHA AND MYELINE ALPHA IN THE TREATMENT OF CERTAIN NEUROSES.}

BY JULIUS ALTHAUS, M.D. BeRL, M.R.C.P. LOND., SENIOR PHYSICIAN TO THE HOSPITAL FOR EPILEPSY AND PARALYSIS, REGENT'S PARK.

Atrempts to reacdy deficiencies in the secretion or nutrition of certain organs of the human body by the administration of analogous substances taken from animals are by no means of recent origin, as is frequently believed, but date back into prehistoric times. Dioscorides has been credited by historians with having been the first to recommend the use of ox-gall for the treatment of constipation; but it appears from the recently published "Papyrus Ebers," translated by Joachim into German, that he derived his knowledge on this subject from old Egrptian sources, for the papyrus just mentioned contains elaborate prescriptions for the use of ox-gall in various diseases. Sperma of animals was likewise used in antiquity, and extracts from the testicles, as well as from the brain, liver, spleen, and lungs of animals, are recommended in the "Tyrocinium Chymicum" of Johannes Beguinus (Amsterdam, 1669). Pepsine, on the other hand, was only discovered by Schwann in 1836, and was introduced into medical practice by Corvisart in 1854 . The most remarkable step in this direction, however, was taken in 1889 by Dr. Brown-Séquard, with whose publications on the hypodermic injection of testicular liquid everyone

1 The rearer will find the meaning of the term "functional disease" 1 The reader will find the meaning of the term "functional disease"
discusser ac considerable length in the Causation of Disease, by Hiscusser ac eonsiderable length
H. Campusll, H.D. London. 1839 . may be supposed to be familiar. He was soon followed by others, who used injections of thyroid juice for the treat ment of myxcedema, of pancreatic extract for diabetes, of cardine for cardiac debility and dyspncea, of extract of supra-renal capsules for Addison's disease, of extract on kidneys for uræmia, and of nervine and cerebrine for diseases of the nervous system (Babes, ${ }^{1}$ Paul, ${ }^{2}$ Hammond, ${ }^{3}$ and Dana $\left.{ }^{4}\right)$. Up to the present time, however, a solid foundation. cannot be said to exist for any of these therapeutical procedures, with the one exception of the treatment of myx. odema with thyroid juice. It therefore appeared to me to be worth while to investigate any medicinal action which might be possessed by extracts of the brain and spinal cord, and 1 will in the following lines simply relate my personal ex. perience in this matter, without entering into criticism of the opinions and practice of others.

In September, 1892, I communicated with Messrs. Brady and Martin, of Newcastle-on-Tyne, requesting them to prepare for me sterilised extracts from the brains as well as from the spinal cords of healthy young animals, and I am very much indebted to them for a considerable expenditure of time and trouble or their part in carrying out my wishes. They have prepared these extracts in the same way as their thyroid extractthat is, by mixing one part by weight of the animal tissues with one part of glycerine and one part of a 0.5 per cent. car. bolic solution. A healthy rabbit is killed by the inhalation of chloroform. The spinal cord is then rapidly dissected out with sterilised instruments and under antiseptic precautions. To 3 grammes of spinal cord matter 3 c.c. $\mathbf{f}$ glycerine and 3 c.c. of the carbolic solution are then added, and the whole is intimately mixed and allowed to stand for a day. On pressing it off the product is found to measure $72 \mathrm{c.c}$. The brain is treated in the same manner: to 8.2 . grammes of brain matter 8.2 c.c. of glycerine and 8.2 c.c. of the carbolic solution are added, the product measuring 20 c c. I have termed the organic extracts thus obtainec myeline alpha and cerebrine alpha-the alpha being added in order to distinguish the brain extract from the animal alkaloid "cerebrine" $\left(\mathrm{C}_{69} \mathrm{H}_{11} \mathrm{~N}_{2}\right)$, which is obtained by treating the protagon of the brain matter with alkalies, or by boiling the fresh brain with baryta water, and then extracting the alkaloid with boiling alcohol from the precipitate; and to distinguish the spinal cord extract from "myeline," which is no chemical compound, but one of the constituents of the central nerve-fibre. The specific gravity of the cerebrine alpha is 1087 and that of the myeline alpha 1082. They both have an acid reaction, and contain organic matters in two. forms-viz., first, matters in solution, and, secondly, matters in suspension, which latter cannot be filtered out undiluted. Messrs. Bradyand Martin havefound on analysis that the former contain small quantities of proteids, giving the xanthoproteid and Millon's reactions. They do not contain phosphoric acid either in combination with bases or with organic compounds. Among the matters in suspension are protagor $\left(\mathrm{C}_{66} \mathrm{H}_{11} \mathrm{~N}_{2} \mathrm{P}_{1}\right)$, lecithine $\left(\mathrm{C}_{44} \mathrm{H}_{90} \mathrm{NPO}\right)$, cerebrine $\left(\mathrm{C}_{69} \mathrm{H}_{11} \mathrm{~N}_{3}\right)$, and protelds. The totalquantity of phosphoric acid present is in excess of that required to combine with the bases. Although insoluble in water, the phosphorised bodies readily split up under the action of alkalies, yielding stearic acid, glycerophosphoric acid, and choline, and are then fairly soluble. Neurokeratine, nucleine, and spermine have been looked for, but not found. Neither preparation has shown perceptible change after having been kept for upwards of three months in stoppered bottles lying on its side in a cool place. Hypodermic injection appears to be necessary, as swallowing these extracts produces no perceptible physiological or therapeutical effects, The gastric juice seems to decompose them and to render them inert, as it does with other animal fluids, such as vaccine, snake-poison \&c. In order to avoid irritation it is best not to inject into the cellular tissue, but into the substance of the muscles, preferably the glutei. After a number of trials I have found a good initial hypodermic dose of both extracts to be five minims. If after such a dose a good effect is perceptible, the same may be continued; but should there be no change the dose may be gradually

1 Babes: Die Behandlung der genuinen Epilepsie \&e. Deutsche Medicinische Wocbenschrift, No. 30. 1892; No. 12, 1893 .

2 Constantin Paul: Expériences sur la Transfusion Nerveuse. Bulletin de l'Acadénie de Médecine, Février, 1892. Du Traitement Bulletin de lacademie de Médecine, Ferrasthénie \&c. Ibid

de la Neurasthenie \&c. Ibid, April, 1893.
Hammond: On Certain Organie Extract

3 Hammond: On Certain Organic Extracts
New York Medical Journal, Jan. 28th, 1893.

Work Medical Journal, Jan. 28th, 1893.

4 Dana: Modern Patbology and the Pathology of
Boston Medical and Surgical Journal, May 18th, 1893 . 